availability of smoothies! User reported outcomes show 93\% feel their views are appreciated and want to attend again. The group now takes place on two sites and also includes inpatients, discharged patients and bereaved relatives.

Wasn't that nice!

The success of the Feedback Group has been due to consistent user steer, good inter-service teamwork, leadership and not being disheartened by initial small attendance (e.g. less than 10).

\section{P-204 'WE ARE ALL IN THIS TOGETHER' BUILDING CAPACITY FOR SERVICE USER INVOLVEMENT IN OUR HOSPICE}

${ }^{1}$ Hannah Wilson, 'Suzanne McArthur, ${ }^{1,2}$ Nikki Reed. ${ }^{1}$ Marie Curie Hospice, West Midlands, Solihull, UK; ${ }^{2}$ University Hospitals of Birmingham NHS Foundation Trust, Birmingham, UK

10.1136/bmjspcare-2018-hospiceabs.229

Background It is important that we understand what matters to our patients and their families. We cannot overestimate the financial cuts and constant social challenges our patients and their families are facing today. Service User Involvement has become a formal requirement for policy and practice in health and social care. Research has identified a lack of consistency with the way service user involvement is implemented within healthcare. It is acknowledged that our clinical priorities and the increasing pressures of time can lead to staff neglecting the importance of service user involvement.

Aim Marie Curie Hospice West Midlands will recognise the importance and will prioritise service user involvement.

Methods Development of a service user group - consisting of both service users and staff. Development of Service User Champions (SUC) within each professional team at the hospice. Development of formal training sessions to be delivered by service users to our SUCs and hospice management team highlighting the importance of service user engagement in current service evaluations and future developments. Formal service user involvement in the development of the hospice strategy.

Results We have already formalised our service user group, which meets regularly. Over the next year, we hope to demonstrate that:

- Service user involvement is at the centre of our practice

- Establish formal Service User Champion roles within hospice MDT

- Demonstrate that we both receive and act on pertinent service user feedback by formally evaluating our implementations

- Facilitate the development of partnership working between all stakeholders under the heading 'We are all in this together' in the development of the hospice strategy.

Conclusion Service user involvement needs to be a priority in health and social care. We hope to demonstrate the benefits of implementing formal processes to ensure this remains a priority at our hospice.

\section{P-205 THE CHALLENGES AND PITFALLS OF ALTERING OUTCOMES FOR FRAIL ELDERLY PATIENTS IN RESIDENTIAL CARE}

${ }^{1}$ Emer Mckenna, ${ }^{2}$ Ali Khan, ${ }^{1}$ Neil Grannon. 'Douglas Macmillan Hospice, Stoke on Trent, UK; ${ }^{2} U H M N$, Stoke on Trent, UK

10.1136/bmjspcare-2018-hospiceabs.230
Aim The main purpose of our project was to assist care home staff with identifying their own residents who may be palliative, opening up ceiling of care/advance care planning discussions, and reducing inappropriate hospital admissions.

Background A survey by BUPA in 2011 found that 72\% of new admissions die within 42 months. We were invited by local commissioners to review four nursing home facilities to identify any gaps in meeting their residents' palliative care needs. Despite heavy encouragement from local commissioners two care facilities declined our input at the beginning. The remaining two care home managers agreed to participate and we completed a baseline review/scoping exercise to understand challenges in maintaining residents in their place of choice. From this individualised review we negotiated next steps in assisting with identification of patients who could die in the next 12 months and look at how this is communicated to all relevant parties.

Results Majority hospital admissions due to infection with underlying morbidity of frailty and dementia. Significant variance in quality of documentation and communication with residents, families and primary care teams. Home A has failed to retain two care home managers since project began highlighting issues with leadership and continuity. The enthusiasm, consistent staffing and ownership of project by staff in Home $\mathrm{B}$ has been vital to this project moving forward. We have completed seven ceiling of care documents since May 2018 and have commenced GSF like meetings monthly.

Conclusion None of what was revealed is unique or novel but is a timely reminder of barriers to transforming outcomes for this vulnerable population. The commissioner has acted as an intermediary/broker and unclear if this has led to suspicion, fear of financial penalties and then refusal and inertia to be part of the project.

\section{P-206 THE ROLE AND IMPACT OF PHARMACISTS WITHIN A HOSPICE'S CARE HOME SUPPORT TEAM}

Michael Kolovetsios, Hawre Yones. ellenor, Kent, UK

\subsection{6/bmjspcare-2018-hospiceabs.231}

The Royal Pharmaceutical Society (2016) reports integrating a pharmacy team in care homes would improve the efficiency, safety, and quality of medicines use for patients; offering immediate support in:

- Polypharmacy

- Antipsychotic prescribing

- Safe transfer of information

- Education, training; and standards

- Palliative and end of life care.

Aims Pharmacists undertake level 3 clinical medication reviews (National Institute for Health and Care Excellence, 2014) aiming to manage and deliver safe, efficient and effective medicines optimisation support to patients, in line with NICE guidelines and local clinical governance (Butterfield \& Shah, 2014; Kinley, Froggatt \& Bennett, 2013; Swift, 2018).

Methods A Clinical Commissioning Group in South East England employs two full-time pharmacists working in partnership with the local hospice's Care Home Support Team to provide specialist palliative medicines information and advice for the organisation. The project currently covers 16 care homes, including 700 to 900 patients. The pharmacists perform 